\section{DIÁNOIA}

LEYVA, GUSTAVO

Comentarios a Categorías y autoconciencia en Kant de Pedro Stepanenko

Diánoia, vol. XLVI, núm. 47, noviembre, 2001, pp. 87-92

Universidad Nacional Autónoma de México

Distrito Federal, México

Disponible en: http://www.redalyc.org/articulo.oa?id=58404705

- Cómo citar el artículo

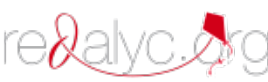

- Número completo

- Más información del artículo

- Página de la revista en redalyc.org

Sistema de Información Científica

Red de Revistas Científicas de América Latina, el Caribe, España y Portugal

Proyecto académico sin fines de lucro, desarrollado bajo la iniciativa de acceso abierto 


\title{
Comentarios a Categorías y autoconciencia en Kant de Pedro Stepanenko
}

\author{
GUSTAVO LEYVA \\ Universidad Autónoma Metropolitana-Iztapalapa \\ leyv@xanum.uam.mx
}

\begin{abstract}
Resumen: El libro Categorías y autoconciencia en Kant de Pedro Stepanenko expone las distintas perspectivas desde las cuales Kant pretendió justificar la objetividad de las categorías. En esta exposición, Stepanenko se ha apoyado en el estudio sobre la génesis de la deducción trascendental que Wolfgang Carl lleva a cabo en su libro Der schweigende Kant. A pesar de que Stepanenko se mueve una y otra vez en dirección de una reconstrucción argumentativa, cabe preguntarse si logra liberarse de la estrategia interpretativa de W. Carl, para la cual los textos de Kant se abordan básicamente como expresión de las intenciones argumentativas del autor, reeditando, al parecer, la vieja divisa del "retorno al texto".
\end{abstract}

Palabras ClaVE: Kant, Stepanenko, Carl, interpretación

Los grandes exponentes de la filosofía clásica alemana continúan despertando un enorme interés en las discusiones contemporáneas. Así, por ejemplo, en él ámbito anglosajón, Robert Brandom a partir de su monumental obra Making it explicit (Cambridge-Londres, 1994), ha sido caracterizado como perteneciente a los "Pittsburgh Neo-Hegelians", y John Mc Dowell, a pesar de sus constantes referencias a Hegel en obras como Mind and World (Cambridge-Londres, 1994), ha sido señalado como un "Neo-Kantian". La influencia de Kant, específicamente, ha sido de enorme significación en los debates en torno a la teoría del conocimiento, la ética, la filosofía política y aún la estética - y esto no solamente en las discusiones en lengua inglesa, sino también en las que tienen lugar en el ámbito continental y, por supuesto, en el iberoamericano. En México especialmente, Kant ha experimentado un renovado interés en los últimos años y ha sido objeto de cuidadosas traducciones y de detallados estudios en libros y artículos de Fernando Salmerón y Luis Villoro y, entre las generaciones más recientes, de Carlos Pereda, Dulce María Granja, María Noel Lapoujade, Isabel Cabrera, José de Teresa, Faviola Rivera, Efraín Lazos, Carlos Mendiola, Julio Beltrán y Pedro Stepanenko, quien ahora nos presenta su libro Categorías y autoconciencia en Kant. Antecedentes y objetivos de la deducción trascendental de las categorías (IIF-UNAM, México, 2000). 
En este libro Stepanenko se propone "exponer las distintas perspectivas desde las cuales Kant intentó justificar la objetividad de este esquema conceptual [esquema que nos permite hablar de objetos], así como los conflictos en los cuales se vio envuelto al intentar conjugarlas" (p. 11). En la reconstrucción de estas diversas perspectivas, Stepanenko se ha basado en el detallado estudio presentado por Wolfgang Carl en Der schweigende Kant. Die Entwürfe zu einer Deduktion der Kategorien vor 1781 (Gotinga, 1989). Habré de detenerme por ello en el análisis presentado por Carl en el mencionado libro, pues creo que en él se suministra la clave para una comprensión más adecuada del libro de Stepanenko que ahora comento.

El libro de Carl partía de la constatación de la incuestionable presencia de la filosofía de Kant en la filosofía analítica contemporánea explicable, según él, porque Kant representa una alternativa a las diversas formas del naturalismo. La pregunta que se le planteaba a Carl era entonces cuál era la posición de Kant frente al naturalismo que en su época se expresaba en el "sistema del empirismo universal" de Hume, según se señala en el prólogo a la Kritik der praktischen Vernunft (AA V, 13). Para Carl, ello se traducía en la necesidad de desarrollar una discusión histórica y sistemática entre Kant y Hume a partir de la alternativa entre naturalismo, por un lado, y filosofía trascendental, por el otro, que, de acuerdo con él, podía ser realizada en el marco de una investigación sobre la historia del desarrollo de la "Deducción de los conceptos puros del entendimiento", la pieza de la filosofía teórica en la que Kant, según sus propias palabras, invirtió mayores esfuerzos (cfr. Carl 1989, pp. 7 y ss.). La conclusión a la que llegó Carl es que una decisión frente a la alternativa naturalismo/filosofía trascendental no podría ser tomada en el marco de una elucidación sobre la historia del desarrollo de esta pieza central de la filosofía teórica. Al mismo tiempo, sin embargo, Carl llegó a la convicción de que la historia del desarrollo de las reflexiones que llevaron a Kant a la deducción de los conceptos puros del entendimiento antes de 1781 eran de un interés no solamente historiográfico, sino también hermenéutico, pues podían contribuir a una comprensión más adecuada de la versión que Kant publicara en 1781 de la "deducción de las categorías". Más específicamente, le preocupaba a Carl desarrollar una lectura de esta pieza de la filosofía teórica kantiana que no considere a ésta orientada a refutar al escepticismo - y, más precisamente, a ofrecer una respuesta al escepticismo de Hume- como parece haberse subrayado con insistencia en la discusión en torno a los llamados "argumentos trascendentales".

En este mismo sentido, Carl deseaba desarrollar una estrategia de lectura e interpretación de Kant que se apartara tanto de la "interpretación selectiva" desarrollada por Peter Strawson en The Bounds of Sense (Londres, 1966) —donde se considera a la deducción trascendental bajo la forma de 
un argumento acerca de las implicaciones del concepto de experiencia en general y, a la vez, como una descripción de los trabajos trascendentales de las facultades subjetivas por medio de las cuales se produce la experiencia, enlazando así a la filosofía y a la psicología, subrayando la necesidad de un "disentangle" de los dos elementos, siendo a la vez conscientes de la presencia de ambos en el texto- como de la "lectura hermenéutica" de Dieter Henrich -empeñada en ofrecer una interpretación consistente y defendible de un argumento en el que en realidad se encuentran entrelazados diversos argumentos, textos y pruebas, en suministrar una lectura que hiciera transparente al texto y desplegara su enorme potencial teórico, propuesta desarrollada en Identität und Objektivität. Eine Untersuchung über Kants transzendentale Deduktion (Heidelberg 1976). Carl, por su parte, se orienta a desarrollar una consideración de la "historia del desarrollo (Entwicklungsgeschichte)" del texto que por un lado, a diferencia de la de Strawson, suministre una unidad al texto comprendiendo así la versión publicada por Kant desde el horizonte de los bosquejos previos y como realización de intenciones que en ellos se expresan, y, por el otro, a diferencia de Henrich, se oriente en la comprensión del texto no por las intenciones del intérprete, sino por las del autor —en este caso, el propio Kant. Así, el estudio del esbozo de deducción contemporáneo a la carta a Herz de 1772, al igual que de los proyectos contenidos en los llamados Manuscritos de Duisburg —cuya redacción se localiza hacia 1775—, lo mismo que la nota conocida con la designación $B 12$ elaborada por Kant muy probablemente en 1780, asumen un papel central en una investigación de esta clase.

En su estudio, Carl muestra así que las reflexiones de Kant en torno a una "deducción de las categorías" parten de la pregunta en torno al "uso real del entendimiento (realer Gebrauch des Verstandes)" formulada de manera clara en su carta a Herz de $1772-$ y es solamente desde esta perspectiva que pueden ser comprendidas cabalmente. Kant propone un criterio para la corrección de este uso señalando que un uso correcto de estos conceptos tiene lugar cuando ellos se encuentran en concordancia con objetos que son accesibles a través de la experiencia. Ello se enlaza con una nueva concepción del papel de dichos conceptos que se consideran, por un lado, como principios formales del conocimiento empírico y, por el otro, como condiciones subjetivas bajo las que se encuentra un concepto posible para nosotros del conocimiento. Estas dos interpretaciones conducen, de acuerdo con Carl, a diversas estrategias para responder a la pregunta planteada en la carta a Herz de 1772 y se enlazan con diversos propósitos de la filosofía teórica de Kant: por un lado, con una deducción "objetiva" que se propone suministrar una prueba de que los conceptos del entendimiento se refieren a los objetos porque aquéllos son condiciones de posibilidad de la experiencia 
- con lo que se determinan a la vez los límites del entendimiento- y, por otro lado, con una deducción "subjetiva" que se orienta a probar que las condiciones subjetivas del pensamiento poseen validez objetiva. No obstante, señala Carl, mientras que la deducción "objetiva" ofrece una respuesta que parte del supuesto de que tenemos experiencia, la deducción "subjetiva" no plantea esta suposición. Ella es más bien una "elucidación de la facultad que llamamos entendimiento" ( $\mathrm{KrV}$, A XVI) en la que el concepto de apercepción desempeña un papel central. Así, según esto, en un caso tenemos una investigación de las condiciones de posibilidad de la experiencia; en el otro, una elucidación de los conceptos fundamentales de la metafísica, una "metafísica de la metafísica", como Kant mismo anota en una carta del 11 de mayo de 1781 a Herz. No obstante, señala Carl, estas distintas lecturas no convergen ni en las premisas de las que parten, ni tampoco en las conclusiones a las que llegan. Ambas se entrelazan en las interpretaciones que Kant da de ellas en la "deducción de las categorías" pero pueden ser aisladas y separadas con precisión justamente a través de una consideración de su Entwicklungsgeschichte.

Siguiendo estas ideas, Stepanenko se propone exponer en su libro, en primer lugar, la pregunta acerca de la objetividad de los conceptos puros del entendimiento tal y como Kant la expresara en la ya mencionada carta a Herz de 1772. Posteriormente, siguiendo a Carl, analiza con detalle las reflexiones en las que se encuentra una primera respuesta a esta pregunta. En este punto, a pesar de la gran influencia que se advierte del estudio de Carl a lo largo de todo el texto de Stepanenko, éste intenta avanzar en una interpretación de los esbozos de la deducción en los Manuscritos de Duisburg (1775) y en la nota $B 12$ (1780) que se aparta de la de Carl. No obstante, al igual que Carl, se afana en mostrar cómo la idea de la deducción "objetiva", tal y como Kant la expone en el prólogo a la primera edición de la Crítica de la razón pura, aparece entrelazada con ideas y argumentos que en sentido estricto pertenecen a otro proyecto de deducción. Así, en el quinto capítulo de su libro, Stepanenko se propone ofrecer, en una vertiente inaugurada por Dieter Henrich, un enfoque de los conceptos puros del entendimiento que muestre la necesidad de éstos sin recurrir al concepto de experiencia y remita solamente al concepto de autoconciencia. A lo largo de todo el libro, Stepanenko nos ofrece un estudio detallado, muy informado y altamente sugerente de las distintas perspectivas y tentativas empleadas por Kant para justificar y probar la validez objetiva del esquema conceptual que nos permite hablar de objetos en la experiencia, es decir, de los diversos ensayos y proyectos de la deducción trascendental de las categorías o, más precisamente, de los antecedentes y objetivos de la deducción trascendental de las categorías, según se señala ya desde el subtítulo de la obra. A pesar 
de su cercanía con el estudio de Carl, el de Stepanenko muestra también un perfil propio. Así, por ejemplo, su interpretación de la deducción trascendental de las categorías se aparta —en esto siguiendo de nuevo a Carl— de la interpretación predominante en la discusión en torno a argumentos trascendentales que considera a la filosofía de Kant como una refutación del escepticismo de Hume - por ejemplo, en autores como Barry Stroud, Jonathan Bennet, et. al. No obstante, al mismo tiempo, a diferencia de Carl, quien llega a la conclusión de que la meta de la filosofía trascendental no era la refutación al escepticismo, sino la de establecer las condiciones bajo las que se encuentra una crítica a las fundamentaciones empiristas del conocimiento, Stepanenko señala que el contrincante de la deducción sería, si se hablara en un lenguaje más actual, el "convencionalista" que "considera al marco lingüístico dentro del cual hablamos de los objetos de la experiencia tan sólo como una alternativa entre otras" (p. 17).

Quizá cabría preguntarse si la manera que Carl y Stepanenko tienen de leer a Kant no resulta en ocasiones demasiado inmanente y ligada al texto —o, mejor dicho, a la génesis del mismo-, animados por la pretensión de comprender el texto kantiano como expresión de intenciones argumentativas del autor que se delinean en forma unitaria y consistente sobre el trasfondo de un juego de textos y de bosquejos que se dispersan, se enlazan y se unen, pero también se distinguen y se oponen, reeditando con ello la divisa del "retorno al texto", de la búsqueda de las intenciones originales del autor, que la hermenéutica clásica hiciera suya en otro momento y que la hermenéutica contemporánea considera no solamente ingenua, sino también acaso imposible e insostenible. Cabría recordar al respecto, que en su libro clásico sobre Kant ya mencionado, Dieter Henrich se preguntaba cómo debían ser leídos e interpretados los textos filosóficos, especialmente los clásicos. Distinguía tres procedimientos posibles: el primero de ellos es aquel que ofrece una paráfrasis explicativa, imprescindible si se quiere comprender el texto; el segundo, asume la forma de un comentario genético orientado a exponer el modo en que el autor concibió su propio texto, en qué situación histórica y filosófico-intelectual surgió éste, esforzándose por comprenderlo desde la perspectiva de su propio autor; y el tercero, finalmente, se propone una reconstrucción argumentativa que abra el texto, clarificando conceptos equívocos, explicitando y desarrollando premisas y argumentos no expresados - $\mathrm{o}$ expresados en forma insuficiente, incoherente o poco plausible- en el texto, integrándolo - y esto es algo que no señala Henrich - en el horizonte de una discusión contemporánea al mismo tiempo en que se evalúan sus pretensiones de verdad. En este punto, el propio Henrich - cuya lectura se acerca más a una reconstrucción argumentativa- reconoce que algunos textos innovadores como el de Kant 
son textos más bien poco claros y que por ello su reconstrucción argumentativa debe ser considerada en último término sólo un trabajo preparatorio para una interpretación que se desplaza perpetuamente hacia un futuro indeterminado. Así entendida, la reconstrucción suministra solamente una variante de aproximación al texto - acaso la mejor, la que lo convierte en más coherente, defendible en lo que se refiere a sus pretensiones de verdad y relevante para las discusiones del presente. Quizá la lectura de Stepanenko despierte en ocasiones la impresión de encontrarse demasiado cerca de un comentario genético; es preciso señalar, sin embargo, que su análisis se mueve una y otra vez en dirección de una reconstrucción argumentativa, produciendo como resultado una reflexión que constituye, estoy seguro, un ejemplo de la seriedad y del rigor académico de la filosofía que realizan los jóvenes académicos mexicanos hoy en día.

Recibido: 21 de junio de 2001

Aceptado: 25 de junio de 2001 